\title{
روية مستقبلية للنهوض بالسياحة الرياضية في ضوء التحديات المعاصرة
}

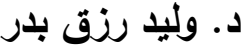

مدرس بقسم الإدارة الرياضية والترويح

كلية التربية الرياضية- جامعة أسوان

\section{نسرين قرشي شلتوت خليفة}

معلم تربية رياضية بإدارة شلاتين التعليمية
أ.د. عادل محمد عبد المنعم مكي

أستاذ الإدارة الرياضية وعميد كلبة التربية

$$
\text { الرياضية }
$$

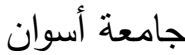

د. محمد حامد فتحي

مدرس بقسم الإدارة الرياضية والترويح

كلية التربية الرياضية - جامعة أسوان الادرة الرياض ولروبن

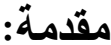

تعتبر السياحة من أكبر الصناعات في العصر الحالي حيث تعتمد عليها بعض الدول في زيادة خطط التتمية ودعم اقتصاديتها، فالسياحة لم تعد تقتصر على زيارة الأماكن الأثرية التاريخية فقط ولكن أصبح هناك اتجاه بربط السياحة بالرياضة حيث تعتبر الرياضة أكبر ظاهرة اجتماعية في العالم فهي مرتكز هام من مرتكزات التنشيط السياحي في الوقت الحالي فهذا يجعل السياحة الرياضية تجمع بين أكبر ظاهرة

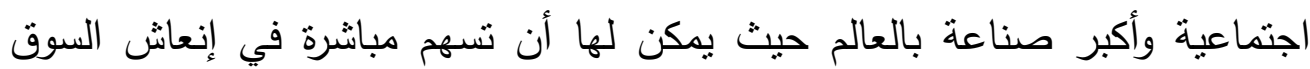
السياحي وفقاً للتحديات المعاصرة. السياحة: هي ظاهرة إجتماعية كبيرة حيث تترك آثارها على مختلف نواحي الحياة في المجتمع الذي يتجه بقوته ونشاطه إلى التتمية السياحية، حيث تتمنل الآثار الإجنماعية

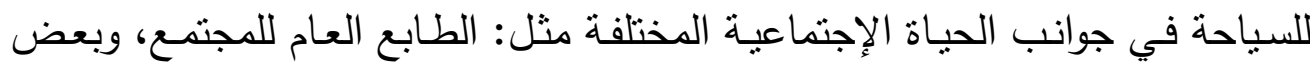
الظـواهر الإجتماعيـة، والعـادات والتقاليد الموجهـهـ لسـلوك الأفراد، ويرجـع ذلـك إلـى التداخل بين المواطنين والسائحين، خاصـة من لهم علاقة مباشرة مـع السائحين مثل: العاملين بشركات السياحة والفنادق، والإرشاد السياحي، ولهذا يتم اختبار هؤلاء العاملين

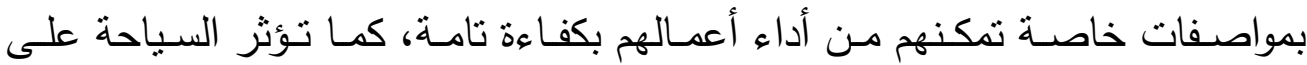
المجتمع الدولي، بإفتشاء جو من السـلام والأمن العالمي، ممـا يخفف من حدة التوتر 
الدولي، ويزيد روح المودة والتفاهم العالمي بين المجتمعات والثعوب المختلفة (11 : (rT- ro أهمية السياحة: تعتبر السياحة لها أهمية كبرى تتمنل في : - تهدف السياحة إلى المساهمة فى دعم الإقتصاد المحلى والعالمى . - جذب رؤوس الأموال إلى البلد من حيث العملات الصعبة ورؤوس الأموال الضخمة. - تشاعد فى تشغيل عدد كبير من الأيدى العاملة والقضاء على البطالة . - تعتبر السياحة سوق زاخر بالصناعات المختلفة والتجارة والزراعة .

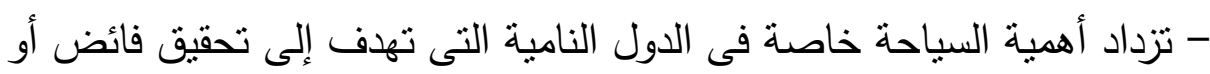
موازنة

في مجال ميزان المدفوعات وتحقيق فائض فى مجال العملة الصعبة . -السياحة كصناعة لها أهميتها الخاصة تستمد من تأثثرها على بنيان وأداء

$$
\text { الإقتصادالقومى. }
$$

تشمل السياحة جميع الأنشطة الإقتصادية في الدول وخارجها فهى تؤئز وتتأثر بنشاط

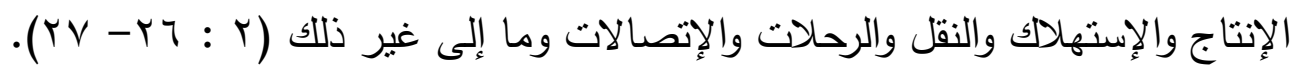
السياحة الرياضية: وتعتبر السياحة الرياضية من أهم أنواع السياحة التي تناهم بشكل الإلى

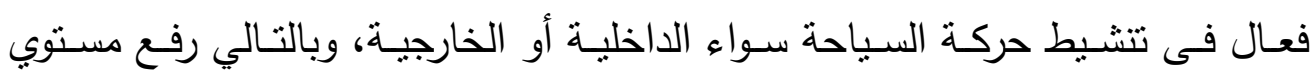
الإقتصاد القومي عن طريق إقامة البطولات والمسابقات الرياضية، لجذب أعداد كبيرة

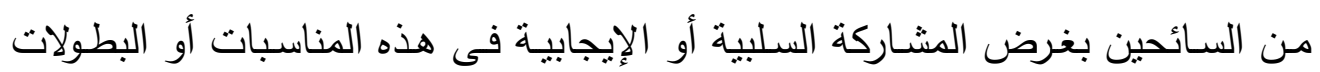

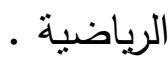
وقد ظهر هذا النوع مـن السياحة (السياحة الرياضية) وانتشر في كثير من الدول،

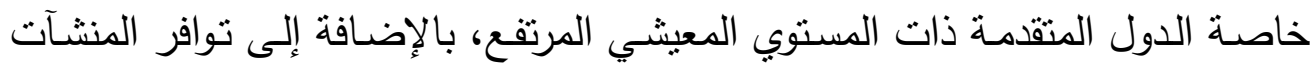

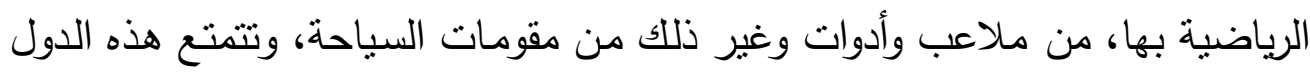
بمقومات عديدة للسياحة مثل الطقس المناسب لممارسة الألعاب والرياضـات المختلفة مدئ 
والقرى الرياضية والأولمبية والسواحل الرياضية والموقع الجغرافي الذي ينوسط الكثير

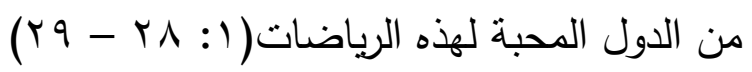
أهمية السياحة الرياضية: تتضح أهمية السياحة الرياضية بأنها تمثل أحد أهم عوامل الجذب السياحي الحديثة التي تحقق النتوع والتغير في مصادر الجذب السياحي لمصر، حيث أن المجال الرياضي الذي كان منذ القدم أحد الوسائل الهامة للتعارف والترويح عن النفس وإظهار القوة البدنية أصبح الآن أحد الوسائل السياحية التي يتهافت عليها

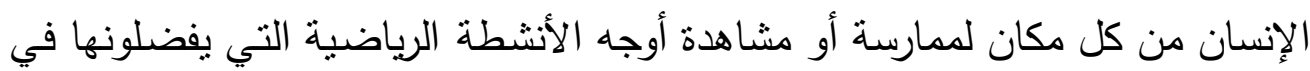
بلد ذات طبيعة سياحية وموارد وعوامل جذب سياحي، فيسهم ذلك في نتشيط حركة

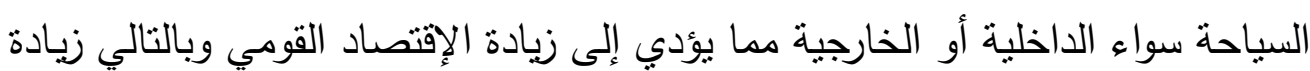

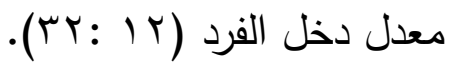
التحديات المعاصرة: تتعدد التحديات المعاصرة لاي دولة فنوعية التحدي نفسه هي التي تحدد حجم الخطر التي تتعرض له هذه الدولة أو ذلك المجتمع، فبعض التحديات نؤثر

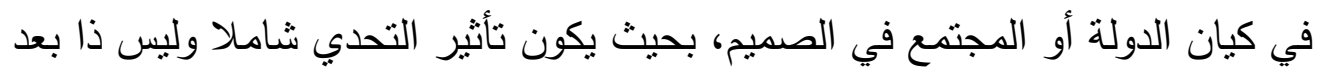

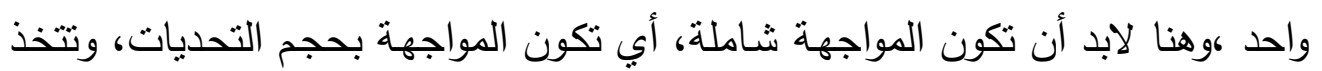
التحديات عدة أشكال، وأهمها: - التحديات الاقتصادية. - التحديات التقافية. - التحديات المعلوماتية. - التحديات الاجتماعية. - التحديات البيئية. - التحديات التكنولوجية (1 (1:7). ومن خلال ما سبق يري الباحثون أن السياحة الرياضية من أهم أنواع السياحة التى تعمل على زيادة الجذب السياحي مما لها دور كبير في استمتاع الفرد وذلك يرجع الى لى الترفيه والترويح الناتج عن ممارسة الرياضة ومن ثم لابد من توفير الامكانات والأدوات والأجزة واماكن تتظيم المسابقات والبطولات الخاصـة بالسياحة الرياضية محلياً ودولياً مما له أثر كبير في الإقتصاد القومي لمصر . 
كما تعتبر التحديات المعاصرة التى مرت بها مصر في الفترة الأخيرة لها أثز كبير على

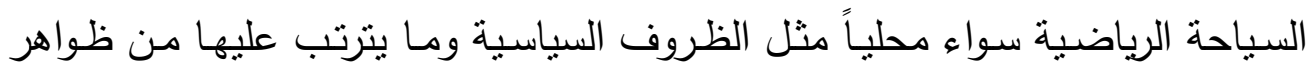
العنف والارهـاب، والظروف الإقتصـادية ومـا يترتب عليها من إنخفاض سعر العملة المحلية، وظروف اجتماعية وما يترتب عليها من بطالة واتساع قاعدة محدودي الدخل أو دولياً مثل التكتلات الإقتصادية وبرتكولات التعاون بين الدول الأخرى وكذلك الثورة التكنولوجيـة المعلوماتيـة تدفق المعرفة بشكل متسـارع ومتواصـل في مجـال السياحة

$$
\text { الرياضية وإرتفاع سعر العملات الأجنبية. }
$$

ومن ثم تعتبر السياحة الرياضية إحدى الوسائل الهامة في الترويج السياحي فهي أحد أهم عوامل الجذب السياحي الحديث التي تحقق التتوع والتغيير في مصـادر الجذب السياحي لمصر فلذلك يجب الإهتمام بتتشيط عوامل جذب السياحة الرياضية في ضوء التحديات المعاصرة التى تمر بها مصر، فهذا يؤدي الى إزدهار الاقتصـاد القومي ومن ثم القدرة على الإستثمار في المجال الرياضي وتتشيطه مما يجعل مصر في الصدارة بين دول العالم في مجال السياحة الرياضية ـ لمثل مشكلة البحث: - من دول

تعتبر السباحة الرياضية من أهم أنواع السياحة التي تسـاهم بشكل فعال فى تتشيط

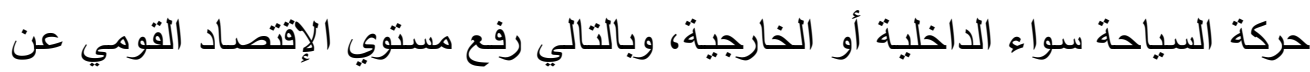

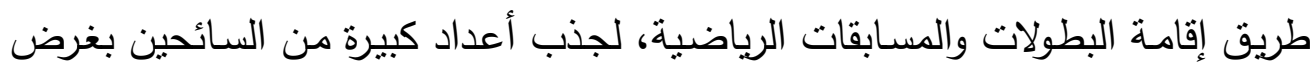

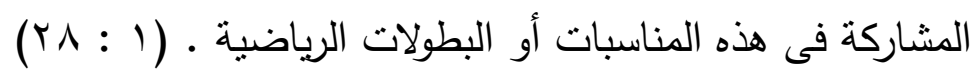
ولكن هنالك بعض التحديات التى تُؤثر على حركة السياحة الرياضية داخل الدول وقلة

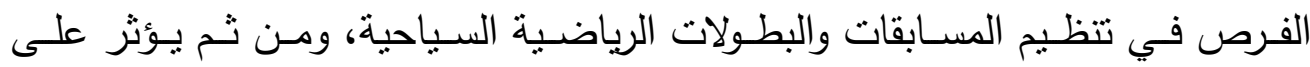
الاقتصاد القومي وعمليات الإستتمار وفرص العمل المتاحة لجميع العاملين في مجال السياحة الرياضية. ومن خلال ما سبق وبعد اطلاع الباحثون على العديد من المراجع والأبحاث العلمية لاحظوا أن مصر تعتبر من الدول التى تتمتع بمقومات نجاح السياحة الرياضية ولكن 
الظروف التى مرت بها مصر من تحديات معاصرة محلياً وعالمياً أثرت على السياحة الرياضية بشكل كبير •

ومن هنا تبلورت فكرة هذا البحث وهي : رؤية مستقبلية للنهوض بالسياحة الرياضية في ضوء التحديات المعاصرة، لما لها من أهمية كبرى في التخطيط والتتفيذ لبرامج السياحة الرياضية والتي تعد من أهم عوامل الجذب السياحي . أهمية البحث: الباهية

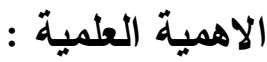

يعتبر هذا البحث إضـافة علمية جديدة في مجال السياحة الرياضية، وقد يساهم في توجيه الباحثنين إلي إجراء أبحاث علميـة أخري تتـاول الجوانب التي لم يتعرض لها البحث الحالي مما يسهم في تقدم السياحة الرياضية وتحقيق أفضل النتائج في مجال السياحة الرياضية.

الأهمية التطبيقية :

النتائج التي يمكن التوصل إليها في هذا البحث قد تفيد في عمليات التخطيط الجيد لبرامج السياحة الرياضية مما يؤدي الى النهوض بالسياحة الرياضية حيث يكون له أثر هئر

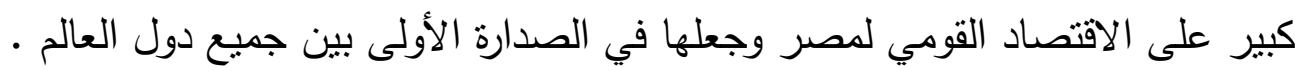
هدف البحث:

يرهف البحث الى التعرف على الرؤية المستقبلية للنهوض بالسياحة الرياضية في ضوء التحديات المعاصرة وذلك من خلا : - - واقع السياحة الرياضية في جمهورية مصر العربية.

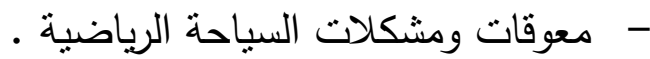

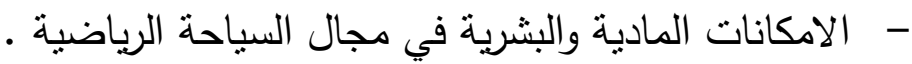
- التحديات المعاصرة التى تؤثز على السياحة الرياضية محلياً وعالمياً .

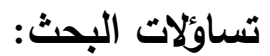

- ما ماقع السياحة الرياضية في جمهورية مصر العربية؟ 


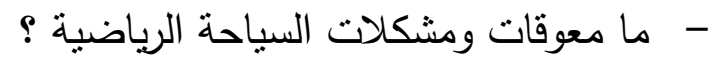

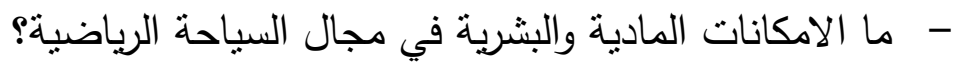

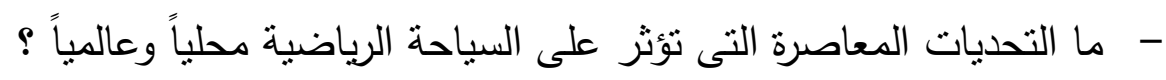

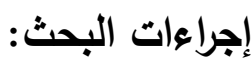

\section{منهج البحث :}

استخدم الباحثون المنهج الوصفي بإسلوبه المسحي نظراً لملائمته لطبيعة إجراءات

$$
\text { مجتمع البحث: }
$$

أنتـتمل مجتمـع البحث على العـاملين بـوزارة السياحة والأخصـائيين الرياضيين بوزارة الثباب والرياضة واعضاء هيئة التدريس فى مجالي الادارة الرياضية والسياحة . عينة البحث: - n

تم اختيار عينـة البحث بالطريقة العشوائية واشتملت على ( (10) من العاملين بوزارة

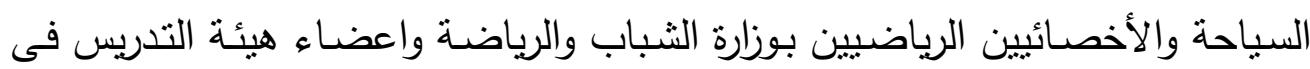
مجالى الادارة الرياضية والسياحة كعينة أساسية، وتم اختيار عدد(· •r) من العاملين

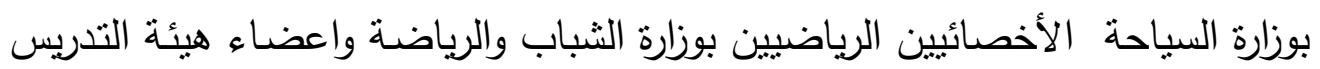

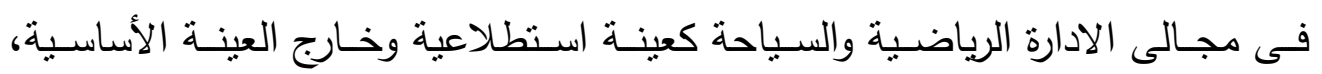
ويتضح ذلك من خلال جدول رقم( (1). 
جول (1)

توصيف عينة البحث

\begin{tabular}{|c|c|c|c|c|}
\hline الاجمالي & العينة الاستطلاعية & العينة الاساسية & الإدارات & 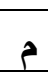 \\
\hline 7. & 1. & 0. & الاخصائيين الرياضيين بوزارة الثباب والرياضة & 1 \\
\hline 7. & 1. & 0 . & العاملين بوزارة السياحة & r \\
\hline 7. & 1. & 0 . & اعضاء هيئة التدريس & $r$ \\
\hline 11. & $r$. & 10. & 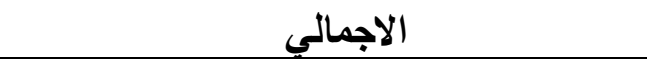 & \\
\hline
\end{tabular}

أدوات ووسائل جمع البيانات :

- السجلات والوثائق الخاصة بالسياحة الرياضية. - المقابلة الشخصية.

- استمارة استبيان السياحة الرياضية من تصميم الباحثة بهدف الوصول الى روئية مستقبلية للنهوض بالسياحة الرياضية في ضوء التحديات المعاصرة. خطوات بناء استمارة استبيان السياحة الرياضية: 1- تحديد محاور استبيان السياحة الرياضية: من خـلال المسـح المرجعي للمراجع والدراسـات المرتبطة المتاحة قام الباحثون بوضـع المحاور المقترحة للاستبيان مرفق(Y) للعرض على الخبراء من من تتوافر فيهم بعض الشروط الآتية: - م

- يكون عضو هيئة تدريس بدرجة أستاذ دكتور تخصص ادارة رياضية أو سياحة (أكاديمي) - أن يكون احد المسئولين فى مجال السياحة الرياضية. - تم عرض المحاور المقترحة فى صورتها الأولى مرفق(Y) على عدد (T) محكمين

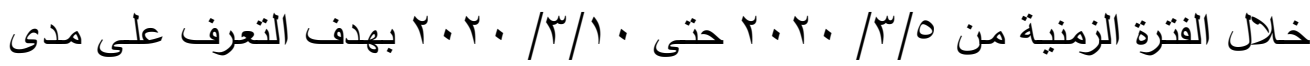
مناسبة المحاور المقترحة للاستبيان. ويتضـح مـن مرفق (r) والخـاص بـرأى السـادة المحكمين فى مـدى مناسبة المحساور المقترحة للاستبيان أنه تمت موافقة الخبراء على جميع المحاور المقترحة حيث حصلت 


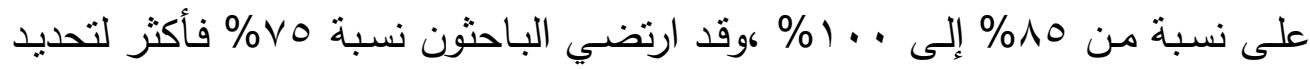
المحاور النهائية للاستبيان.

r. أقتراح عبارات لكل محور من محاور استبيان السياحة الرياضية: وصـاغ الباحثون عبارات الاستبيان فى ضوء الفهم والتحلبل النظرى لكل محور وقد استرشد الباحثون بالاستبيانات الواردة بالدراسات السابقة وتم عرض المحاور والعبارات الخاصـة بكل محور على الخبراء مرفق(1) للتحقق من الصدق المنطقى (المحتوى)

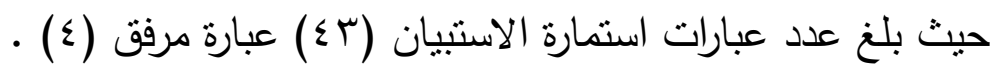

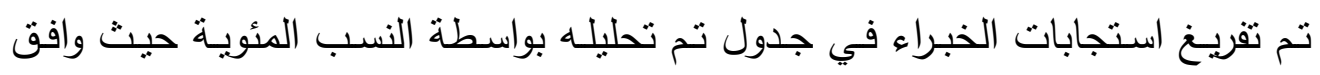
جميع الخبراء على محاور الاستبيان وعباراته مع حذف عبارة رقم (Y ،ه) من المحور

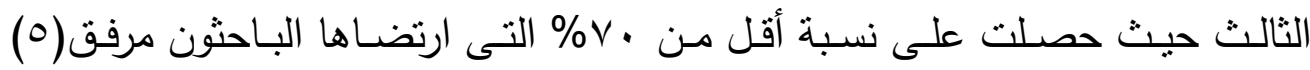
ليصبح عدد عبارات الاستبيان في صورته النهائية (1) (1) عبارة ووضع أمام العبارات

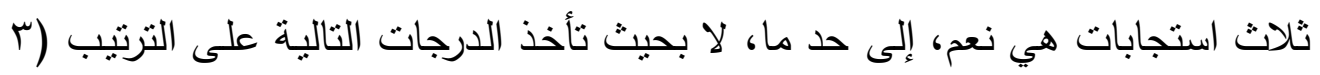

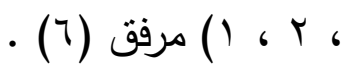
المعاملات العلمية لاستبيان السباحة الرياضية: صدق استبيان السباحة الرياضية: صدق الاتساق الداخلى لاستبيان السياحة الرياضية: تم التحقق من صدق الاستبيان بإستخدام لاتساق الداخلى لمحاور الاستبيان وعباراته

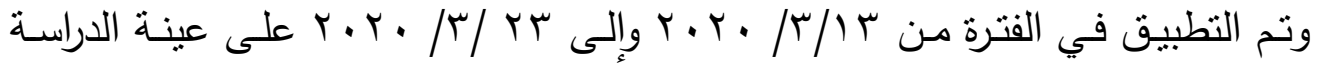
الاستطلاعية وقوامها (· (r) فرداً من العاملين بوزارة السياحة والأخصائيين الرياضيين بوزارة الثباب والرياضـة واعضـاء هيئة التدريس فى مجالى الادارة الرياضية والسياحة

$$
\text { بالخطوات الأتية : بام الباحن. }
$$

حساب معامل الارتباط بين درجة كل عبارة والدرجة الكلية للمحور ، وحساب معاملات الارتباط بين مجموع درجات كل محور والدرجة الكلية للاستبيان. 


\section{جدول (ץ)}

معاملات الارتباط بين درجة كل عبارة من عبارات الاستبيان والدرجة الكلية لكل محور من محاور الاستبيان

$\boldsymbol{r} \cdot \dot{\varphi}$

\begin{tabular}{|c|c|c|c|c|c|c|c|}
\hline المعاصرة الموئثرة & م & وبشيات مادية & م & ومشكوقات & م & واقع السياحة مصر & م \\
\hline 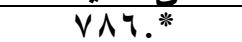 & 1 & 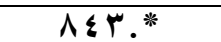 & 1 & $\wedge 9 . . * *$ & 1 & . . $\wedge \vee \& *$ & 1 \\
\hline V.\&.** & $r$ & V०V.** & $r$ & VVY.* & $Y$ &.$V \vee q *$ & $r$ \\
\hline \^^.* & $\mu$ & 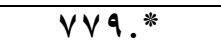 & $\mu$ & $\vee \wedge 1 . *$ & $\mu$ & ..VYq* & $r$ \\
\hline AYr.** & $\varepsilon$ & 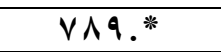 & $\varepsilon$ & $V \varepsilon \bullet . *$ & $\varepsilon$ & . . $\wedge \wedge *$ & $\varepsilon$ \\
\hline$\Lambda \ldots{ }^{*}$ & 0 & $V \varepsilon \varepsilon . * *$ & 0 & $V \ldots{ }^{*}$ & 0 & $\wedge 91 . * *$ & 0 \\
\hline VYI.* & 7 & Vฯ ..* & 7 & V५०.* & 7 & ^৭५.* & 7 \\
\hline VI..** & V & V99.* & V & VVV.** & V & $V \& Y . * *$ & $V$ \\
\hline IYO.* & $\Lambda$ & V^I.* & $\Lambda$ & VYq.* & $\Lambda$ & VI1.** & $\Lambda$ \\
\hline V०५.* & 9 & V.9.* & 9 & VFV.** & 9 & $\Lambda 9 \varepsilon . *$ & 9 \\
\hline УฯА.* & 1. & VqY.* & 1. & $\Lambda \wedge . . *$ & 1. & & 1. \\
\hline \multirow[t]{2}{*}{$\vee \bullet \wedge . * *$} & 11 & & & & & & 11 \\
\hline & & & & & & & $1 \%$ \\
\hline
\end{tabular}

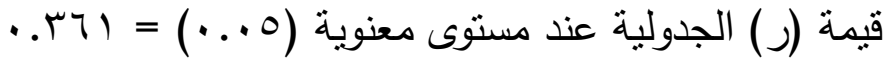

يتضح من جداول السابق أنه تراوحت معاملات الارتباط بين درجة كل عبارة والدرجة التهاته

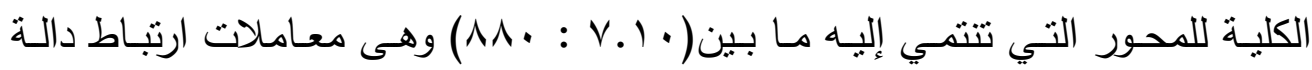
إحصائياً مما بشير إلى الاتساق الداخلي للعبارات.

\section{جدول (r)}

معاملات الارتباط بين كل محور من محاور الاستبيان واللارجة الكلية للاستبيان

$$
r \cdot=\dot{0}
$$

\begin{tabular}{|c|c|c|c|c|}
\hline التحليات المؤثرثة على السياحة & امكانيات مادية ويشرية & معوقات ومشكلات & واقع الساحة الرياضية & المحور \\
\hline$\cdot . \wedge \wedge \neg *$ & $\cdot .9 \cdot r *$ & . .А9ณ* & $. \wedge \vee \leqslant *$ & قيمة معامل الارتباط \\
\hline
\end{tabular}

تراوحـت معساملات الارتبـاط بـين درجـة كـل محسور الدرجـة الكليـة للاسـتبيان مـا

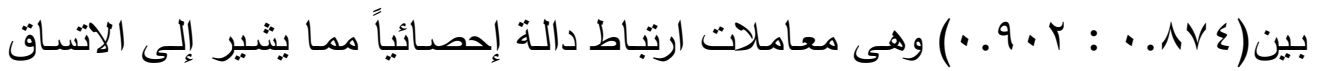

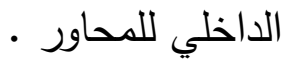




\section{ثبات استبيان السياحة الرياضية:}

قام الباحثون بالتأكد من ثبات نتائج الاستبيان بإعادة تطبيقه مرة أخري بفاصل زمني مقداره 10 يوم علي •r فرد من أفراد عينة البحث الكلية (العينة الاستطلاعية) لإيجاد معامل الارتباط بين كل من القياس الأول والثاني لكل بعد كما هو موضـح بالجدول التالى:

\section{جدول (ع)}

معامل ثبات الاستبيان باستخدام التطبيق واعادة التطبيق لاسبيان السياحة الرياضية $\mu \cdot=\dot{0}$

\begin{tabular}{|c|c|c|c|c|c|c|c|}
\hline \multirow[t]{2}{*}{ قيمة ر } & \multicolumn{2}{|c|}{ التطبيث الثاني } & \multicolumn{2}{|c|}{ التطبيت الاول } & \multirow[t]{2}{*}{ العبارات } & \multirow[t]{2}{*}{ المحور } & \multirow[t]{2}{*}{ p } \\
\hline & انحراف & متوسط & انحراف & متوسط & & & \\
\hline.$\wedge \vee \wedge *$ & rq... & 1.01 & ro.9V & 1.79 & 9 & واقع السياحة الرياضية & 1 \\
\hline. $.710 *$ & 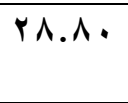 & .99 & rq.1. &..$\wedge \wedge$ & 1. & السبياحة الرياضية ومشكلات & $r$ \\
\hline. $.777 *$ & $1 \leq . \varepsilon$. & $r .01$ & 10.M & 7.79 & 1. & الامكانات المادية & $r$ \\
\hline$. .9 \leqslant 0 *$ & YV. . & $\varepsilon . \varepsilon Y$ & YV.Mr & r.TV & 11 & التحديات المعاصرة & $\varepsilon$ \\
\hline. $.7 r r^{*}$ & 97.1. & $\varepsilon \ldots 1$ & qV.VT & $r .9 r$ & $\varepsilon$. & المجموع & \\
\hline
\end{tabular}

يتضح من الجدول السابق أنه تراوحت قيم معامل الارتباط بين التطبيقين الأول والثاني

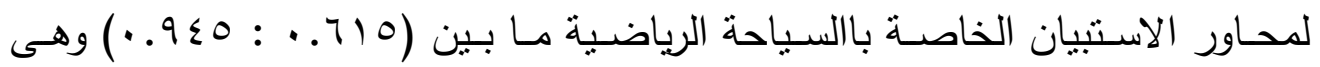
معاملات تشير إلى ثبات الاسنبيان. وبذلك تم وضع الاستبيان في صورته النهائية.

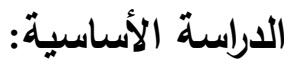

بعد التاكد من توافر كافة الثروط الأدارية والعلمية تم تطبيق الاستبيان على عينة قوامها

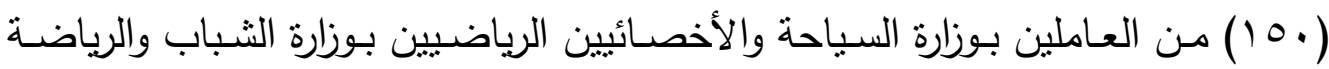

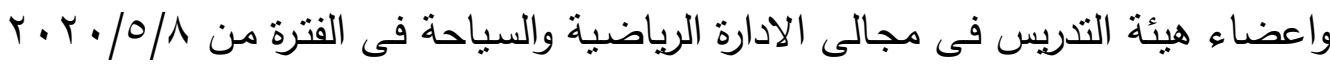

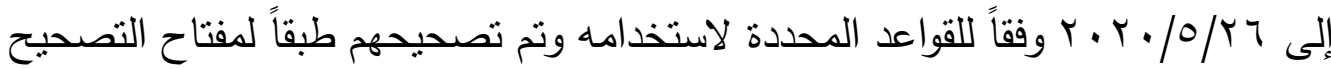




\section{عرض وتفسير ومناقثة النتائج:}

عرض وتفسير ومناقثة النتائج الخاصة بالتساؤل الأول: "ما واقع السياحة الرياضية في جمهورية مصر العربية"؟

وللإجابة على هذا التساؤل تم حساب الدرجة المقدرة والوزن النسبي لدرجة عينة البحث على عبارات استبيان السياحة الرياضية ورصدت نتائج ذلك فى الجدول التالي :

\section{جدول(0)}

التكرارات والدرجة المقدرة والوزن النسبي وكاب لاستجابات عينة البحث على المحور الاول(واقع السياحة الرياضية في ج.م.ع) لاستبيان السياحة الرياضية ن=.

\begin{tabular}{|c|c|c|c|c|c|c|c|c|c|c|c|}
\hline \multirow[t]{2}{*}{ الدلالة } & \multirow[t]{2}{*}{ كاץ } & \multirow{2}{*}{ 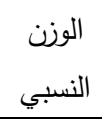 } & \multirow{2}{*}{ الدقدرة } & \multicolumn{2}{|c|}{$y$} & \multicolumn{2}{|c|}{ الى حد ما } & \multicolumn{2}{|c|}{ نعم } & \multirow[t]{2}{*}{ العبارة } & \multirow{2}{*}{ r } \\
\hline & & & & $\%$ & ك5 & $\%$ & ك5 & $\%$ & ك5 & & \\
\hline$\cdots$ & IrV.rE & 19.11 & $\varepsilon \cdot 1$ & $9 . r$. & $1 \varepsilon$ & $1 \leqslant$. & IT & V५.V & 11.0 & 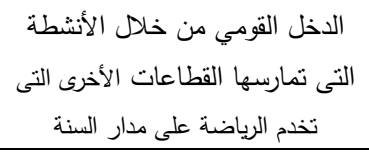 & 1 \\
\hline$\cdots$ & l.r. $\leqslant \Lambda$ & AE.rY & rvq & $19 . r$ & 95 & A.v. & r & VY.. & $1 . .1$ & $\begin{array}{c}\text { المستخدمة في أنثطة السياحة الرئزمات الرياضة } \\
\text { الرياضية } \\
\text { الرياضية }\end{array}$ & r \\
\hline$\cdots$ & $1 \leq 7 . \leq \leq$ & NV.07 & rq & 17.8 & or & $\varepsilon \ldots$ & 7 & Vq.r & 11.9 & 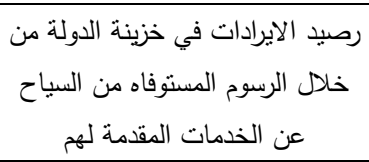 & r \\
\hline$\cdots$ & IrN.or & 10.07 & rNo & $r \cdot . V$ & r & r... & $r$ & VV.T & 11.7 & تتشيط حركة الاتتاج والاستثمار في & $\varepsilon$ \\
\hline$\cdots$ & 107.97 & 19.rr & $\varepsilon \cdot r$ & IT.r & $r$. & $0 . r$. & $\wedge$ & NI.r & IT.Y & تحسين البيئة وتطوير المواقع & 0 \\
\hline$\cdots$ & $179.4 \leq$ & $9 \cdot .199$ & $\varepsilon .9$ & $1 \cdot . v \cdot$ & 71 & $7 .$. & 9 & NT.r. & $1 T .0$ & توفيرفرص عمل جيدة ضمن حدودا & 7 \\
\hline$\cdots$ & 171.1 & 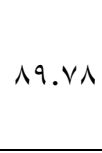 & $\varepsilon \cdot \varepsilon$ & Ir.V & 91 & $0 . r$. & $\wedge$ & Nr... & IT.r & 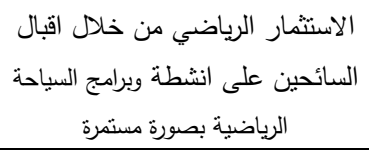 & V \\
\hline$\cdots$ & $199 . V T$ & $91 . \vee \wedge$ & $\varepsilon 1 T$ & Ir.. & 11 &.$v$. & 1 & AV.r. & $1 T .1$ & 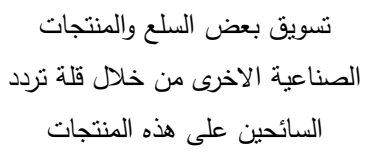 & $\Lambda$ \\
\hline
\end{tabular}




\begin{tabular}{|c|c|c|c|c|c|c|c|c|c|c|c|}
\hline$\cdots$ & $194 . \varepsilon \varepsilon$ & qr.. & ミ1 & $1 . . v$. & 71 & r.V. & $\varepsilon$ & ห५.๖. & $1 \% .$. & 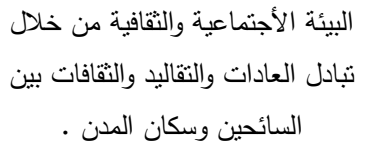 & 9 \\
\hline
\end{tabular}

يتضح من جدول (0) وجود فروق دالة احصائياً بين استجابات الأخصائيين الرياضيين

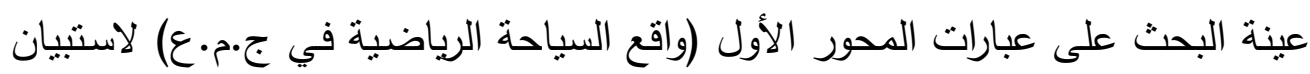

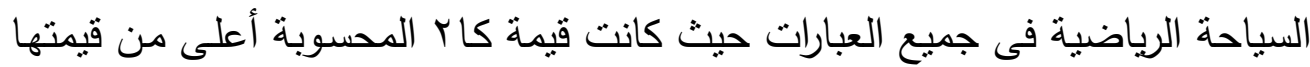

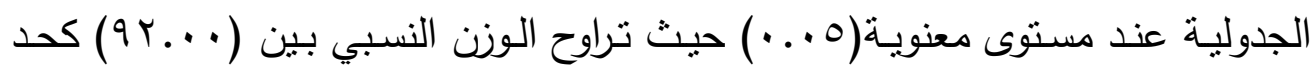

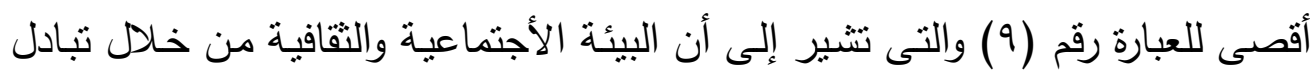

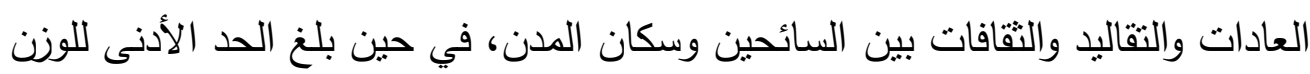

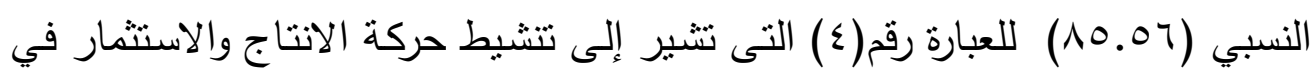
القطاعات الأخري وارجـع البـاحثون هذه النتائج إلى عدم تـوفر كافـة الأنشطة الرياضية بالمشـروعات السياحية في جمهوريـة مصر العربية مما يجعل السياحة الرياضية نؤثز على تتشيط حركة الانتاج والاستثمار في مجال الرياضة والمجالات الاخري وكذلك يؤثر على نقل

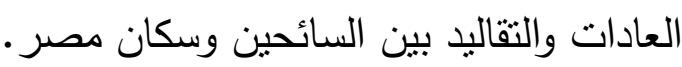

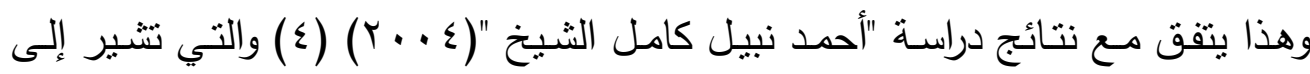
تهذف السياحة الرياضية إلى استثمار المقومات الطبيعية المتوفرة فى جمهوريـة مصر

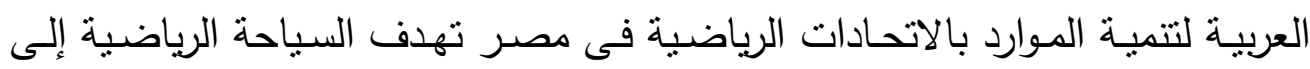
الاستثمار الامنت المتوفرة لتتمية الموارد .

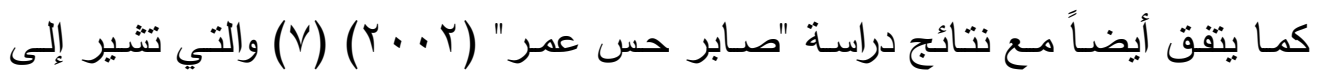
ارتفاع تكلفة ممارسة بعض مناشط الترويح المائي، عدم توافر عوامل الأمن والسلامة وعدم توفر كافة مناشط التروبح المائي •

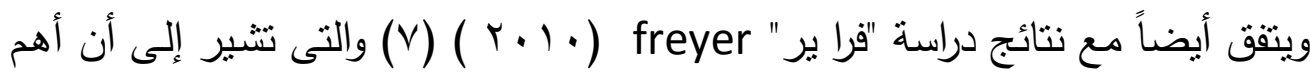

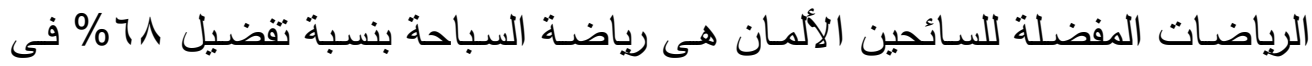

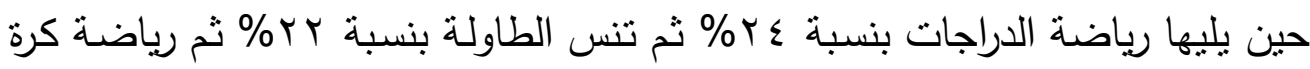


القدم بنسبة ؟ ا \% فى حين تأتى فى نهايـة تلك الرياضـات المفضلة كل من تسلق

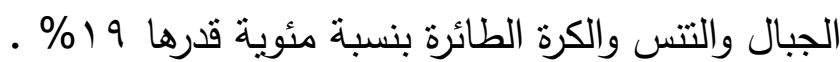
وبهذا يتم الإجابة على التساؤل الأول والذي ينص على وله ما واقع السياحة الرياضية في جمهورية مصر العربية؟ عرض ومناقشة النتايج الخاصة بالتساؤل الثانى : ينص هذا التساؤل على "ما معوقات ومشكلات السياحة الرياضية"؟ وللإجابة على هذا التساؤل تم حساب الدرجة المقدرة والوزن النسبي لدرجة عينة البحث على عبارات استبيان السياحة الرياضية ورصدت نتائج ذلك فى الجدول التالي : 
جدول (7) - (7)

التكرارات والدرجة المقدرة والوزن النسبي وكا بلاستجابات عينة البحث على المحور

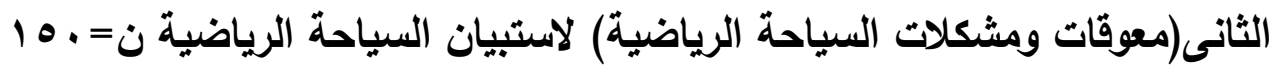

\begin{tabular}{|c|c|c|c|c|c|c|c|c|c|c|c|}
\hline \multirow[t]{2}{*}{ الدلالة } & \multirow[t]{2}{*}{ كاץ } & \multirow{2}{*}{ الوزن } & \multirow{2}{*}{ الدرجة } & \multicolumn{2}{|c|}{$y$} & \multicolumn{2}{|c|}{ الى حد ما } & \multicolumn{2}{|c|}{ نعم } & \multirow[t]{2}{*}{ العبارة } & \multirow{2}{*}{$\hat{\imath}$} \\
\hline & & & & $\%$ & 5 & $\%$ & 5) & $\%$ & 5) & & \\
\hline$\cdots$ & 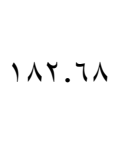 & 94.11 & $\varepsilon 19$ & $7 .$. & 9 & ᄉ.V. & r & NO.r. & I Yᄉ & 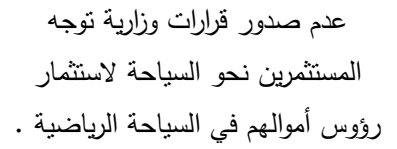 & 1 \\
\hline$\cdots$ & 197.94 & $q \varepsilon \ldots$ & $\varepsilon r r$ & o.r. & $\Lambda$ & V.r. & 11 & AV.r. & וT| & عدم وجود نشريع خاص بالسياحة الرياضية & r \\
\hline$\cdots$ & $194.7 \leq$ & $q r . \leqslant \varepsilon$ & $\varepsilon 17$ & q.r. & $1 \varepsilon$ & $\varepsilon \ldots$ & 7 & ᄉ . . & r. & صعوبة تسويث برامج وأنشطة السياحة & ת \\
\hline$\cdots$ & 17r.1 & س. & $\varepsilon \cdot r$ & $1 \varepsilon \ldots$ & YI & $\varepsilon \ldots$ & 7 & Ar... & אY & من مصادة الرياضية لا يمكن أن تكون مصدر & $\varepsilon$ \\
\hline$\cdots$ & $101 . .1$ & $q r . \leqslant \varepsilon$ & $\varepsilon 17$ & $\varepsilon .$. & 7 & I $\varepsilon . V$. & rr & . & IrY & لا يوجد منهج علمي مختصص للسياحة & 0 \\
\hline$\cdots$ & $1 \leq V \ldots$ & $9 \ldots$ & $\varepsilon .0$ & $1 \ldots$ & 10 & $1 \ldots$ & 10 & $\wedge \cdots$ & Ir. & الأنتمار في مجال السياحة الرياضية يجب & 1 \\
\hline$\cdots$ & $1 \wedge 7.97$ & r. & $\varepsilon 11$ & 11.r. & 18 & r.r. & 0 & NO.r. & IY人 & 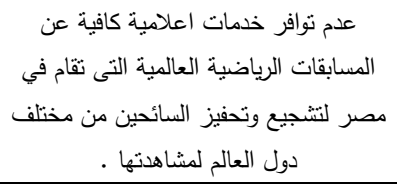 & V \\
\hline$\cdots$ & $r . r . .$. & rr.rq & $\varepsilon . r$ & $\wedge .$. & 1r & $\varepsilon \ldots$ & 7 & $\wedge \wedge .$. & r & 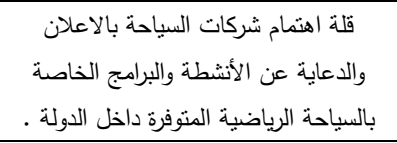 & 人 \\
\hline$\cdots$ & $101 \ldots$ & ᄉV.Vᄉ & مو & 17.8. & ro & r.r. & 0 & $\wedge \cdots$ & Ir. & لاعدم اقامة دورات للعاملين في مجال & 9 \\
\hline$\cdots$ & ץז.rVו & $q r . r r$ & $\leqslant 10$ & V.r. & 11 & ᄉ. V. & 1T & $\Lambda \varepsilon \ldots$ & Iry & ندرة وجود المراكز التى تتظم الدورات العلمية الميل & 1 \\
\hline
\end{tabular}

يتضح من جدول (0) وجود فروق دالة احصائياً بين استجابات الأخصائيين الرياضيين عينـة البحث على عبـارات المحسور الثاني(معوقـات ومشكلات السياحة الرياضـية)

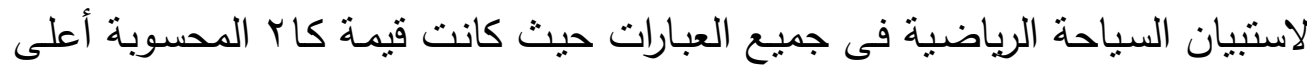
من قيمتها الجدولية عند مستوى معنوية ه... حيث تراوح الوزن النسبي بين (...؟ 9) كدـ أقصى للعبارة رقم (ץ) والتى تثـير إلى عدم وجود تثـريع خـاص بالسياحة 
الرياضية ضمن مجالات الاستثمار والتتمية، في حين بلـغ الحد الأدنى للوزن النسبي

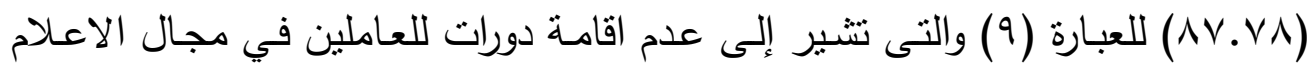
الرياضي عن السياحة الرياضية لنتشيط النمط السياحي. ويرجع الباحثون هذه النتيجة إلى أنه قد تهنم الدولة بأمور أخري في البلد وقلة الاهنمام بتتشيط السياحة الرياضية وثقل العاملين على تقديم هذه الخدمة للسائحين حيث لم يتم

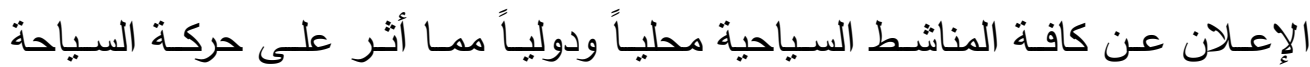
الرياضية في مصر فالاهتمام ببرامج السياحة الرياضية وتتوعها والاعلان عنها بشكل جيد ينعكس بدورة على تفعيل السياحة الرياضية والاستثمار في كافة المجالات .

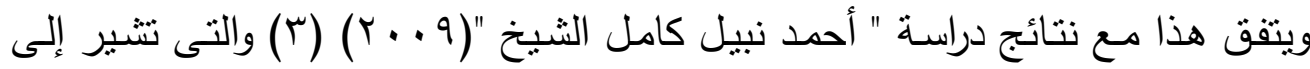
تقويم البرامج الترويحية الرياضية المقترحة لتفعيل السياحة الرياضية للوقوف على مدى كفـاءة هذه البرامج ومـدى تعـاظم الفائدة المرجوة مـن وجودهـا فـى البرامج السياحية

للمساعدة فى تحقيق الرسالة الترويحية للقرى والفنادق بالمدن السياحية المصرية .

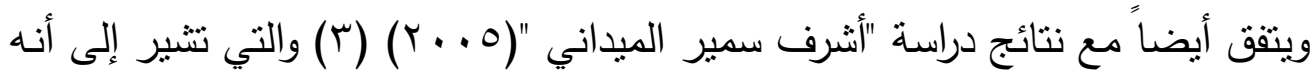
لا يتوفر في مصر الأخصائيون القادرون على العمل في مجال السياحة الرياضية كما لها تشير نتائج هذه الدراسـة إلى وجود قصور في أداء الجهات الإعلامية في دورها في نجاح السياحة الرياضية المصرية كما يعتبر الإعلام والتسويق من الإمكانات الهامـة والمؤثرة في نجاح السياحة الرياضية في مصر •

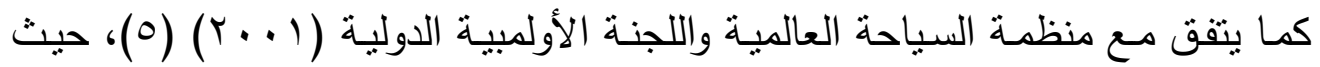
أكدا على أن السياحة والرياضة أداتان قويتان للتتمية وزيادة الإستثمارات في مشروعات البنيـة الأساسية مثنل المطـارات والطـرق والإسـتادات والمجمعـات الرياضـية والفنـادق والمطاعم.

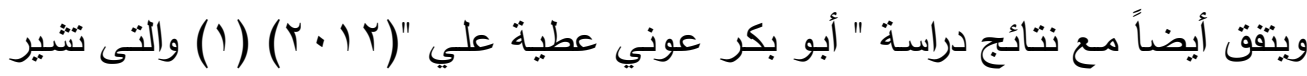
إلى تشجيع الفرق الأجنبية للقدوم إلى البلاد لإقامة معسكرا تهم التذريبية بها بما يسهر 
فى الارتقاء بالسياحة الرياضية، وضع خطة قومية للاستفادة من زيادة أعداد السائحين الوافدين .

وبهذا يتم الإجابة على التساؤل الثاني والذي ينص على ما معوقات ومشكلات السياحة الرياضية؟

عرض ومناقشة النتايج الخاصة بالتساؤل الثالث :

بنص هذا التساؤل على ما الامكانات المادية والبشرية في مجال السياحة الرياضية ؟ وللإجابة على هذا التساؤل تم حساب الدرجة المقدرة والوزن النسبي لدرجة عينة البحث على عبارات استبيان السياحة الرياضية ورصدت نتائج ذلك فى الجد ول التالي: 


\section{جدول (7)}

التكرارات وإلارجة المقدرة والوزن النسبي وكاب لاستجابات عينة البحث على المحور الثالث (الامكانات المادية والبشرية في مجال السياحة الرياضية) لاستبيان السياحة

الرياضية

\begin{tabular}{|c|c|c|c|c|c|c|c|c|c|c|c|}
\hline \multirow[t]{2}{*}{ الدلالة } & \multirow[t]{2}{*}{ كاr } & \multirow{2}{*}{ الوزن النسبي } & \multirow{2}{*}{ المقدة } & \multicolumn{2}{|c|}{$y$} & \multicolumn{2}{|c|}{ الى حد ما } & \multicolumn{2}{|c|}{ نعم } & \multirow[t]{2}{*}{ العبارة } & \multirow{2}{*}{ r } \\
\hline & & & & $\%$ & ك5 & $\%$ & 5) & $\%$ & 5) & & \\
\hline$\cdots$ & $T \varepsilon .1 Y$ & ov.11 & rov & rE.TV & or & אז.990 & 19 & $7 .$. & 9 & لخدمة السياحة الرياضية الرياضية الحالية صالحة & 1 \\
\hline$\cdots$ & IAV.r & $\varepsilon \ldots$ & 11. & Ат... & 149 & ^... & Ir & $7 .$. & 9 & 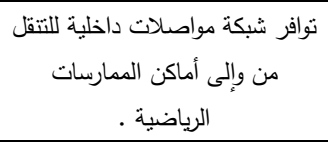 & $r$ \\
\hline$\cdots$ & $17 . .71$ & זוז & 114 & Nr... & Tr & Ir... & 11 & $7 .$. & 9 & تلم الصيانة الدورية للمنشآت & r \\
\hline$\cdots$ & ד. & 纟r.।1 & $19 \varepsilon$ & VA. $7 \mathrm{~V}$ & 111 & אז.זו & $r$. & ^... & ir & تحقق أهداف السباحة & $\varepsilon$ \\
\hline$\cdots$ & r.9.9 & $\leqslant 7 \ldots$ & $r \cdot V$ & VA... & $11 \mathrm{~V}$ & $7 .$. & 9 & $17 \ldots$ & $r \varepsilon$ & $\begin{array}{c}\text { توافر الإداريين المؤهلين لععمال } \\
\text { الإدارية الخاصة بالسياحة } \\
\text { الرياضية. }\end{array}$ & 0 \\
\hline$\cdots \cdots$ & ITV.0T & $\varepsilon \varepsilon \ldots$ & 119 & VT.TV & 110 & $1 \varepsilon .7 V$ & rr & $\wedge .7 \mathrm{~V}$ & r & المتافرات الكوادر المؤهلة لتنظيم & 7 \\
\hline$\cdots$ & $1 \% q . .1$ & $\varepsilon \varepsilon .7 V$ & $r \cdot 1$ & VA. TV & 111 & А.TV & r & IT.TV & 19 & 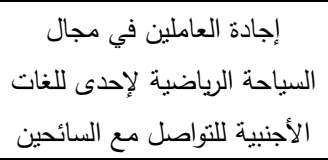 & V \\
\hline$\cdots$ & $101 . Y \leq$ & $\varepsilon r .11$ & $1 \wedge \varepsilon$ & $\wedge . .7 V$ & $|r|$ & r" & $1 \leq$ & $1 \ldots$ & 10 & 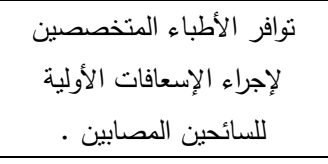 & $\Lambda$ \\
\hline$\cdots$ & $1 \leq V .07$ & & 197 & $\wedge \ldots$ & ir. & rr & $1 \varepsilon$ & $1 . .7 \mathrm{~V}$ & 17 & توافر مرثدون باحيون على تامة بالسياحة الرياضية. & 9 \\
\hline$\ldots$ & IVA.IT & $\{1.07$ & $11 \mathrm{~V}$ & $\wedge \varepsilon .7 V$ & ITV & $7 .$. & 9 & & $1 \varepsilon$ & 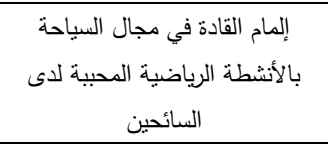 & 1 \\
\hline
\end{tabular}

يتضح من جدول (T) وجود فروق دالة احصائياً بين استجابات الأخصائيين الرياضيين عينـة البحـث على عبـارات المحسور الثالث (الامكانـات الماديـة والبشـرية في مجـال السياحة الرياضية) لاسنبيان السياحة الرياضية فى جميع العبارات حيث كانت قيمة 
كاب المحسوبة أعلى من قيمتها الجدولية عند مستوى معنوية ه . ..، حيث تراوح الوزن

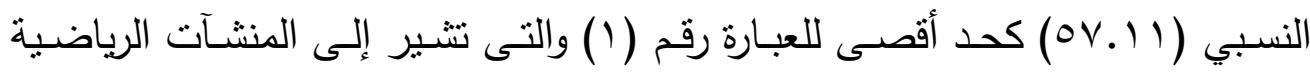

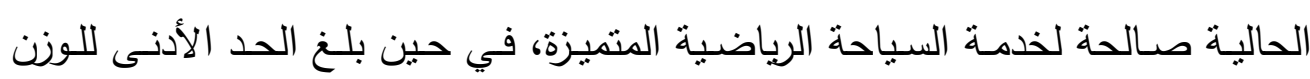
النسبي( ( . . ع) للعبارة رقم (Y) التى تشير إلى توافر شبكة مواصلات داخلية للتنقل

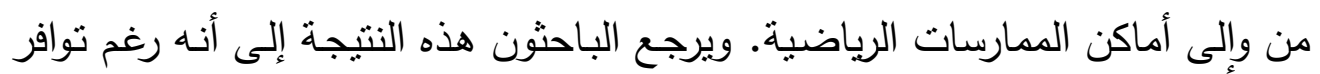
بعض الإمكانات المادية والبشرية إلا أنها غير كافية لإقامة مختلف البرامج الرياضية

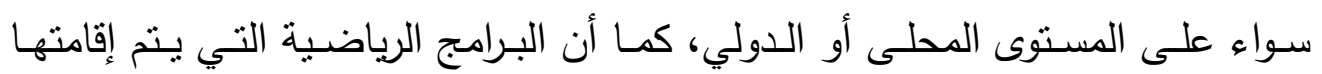
لايراعى فيها الرغبات المختلفة للسائحين وعدم ملاءمتها لنقافات السائحين المختلفة .

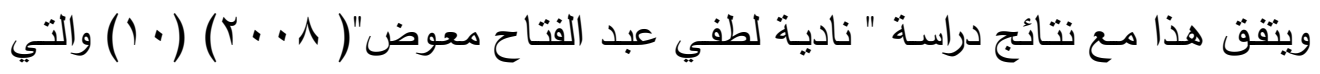
تشـير إلـى تـوافر الإمكانـات الماديـة والبشـرية يسـاعد على إقامـة البـرامج الرياضـية

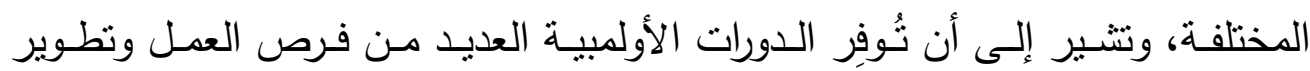

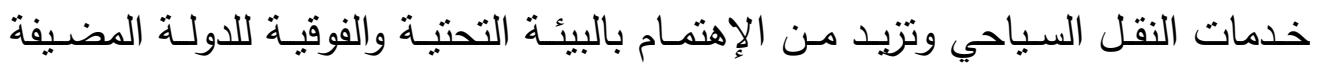

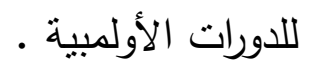

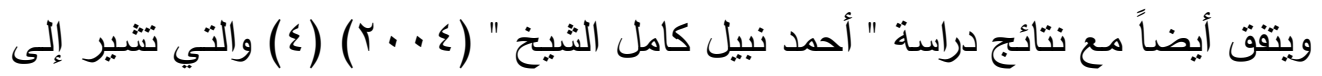
أنه لاتوجد برامج للسياحة الرياضية موضوعة من قبل الإتحادات الرياضية، وأنه لايتم

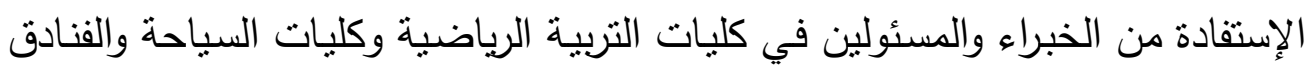
عند وضع برامج السياحة الرياضية التي تشرف عليها الإتحادات الرياضية في مصر • وبهذا يتم الإجابة على التساؤل الثالث والذي ينص على ما الامكانات المادية والبشرية في مجال السياحة الرياضية ؟

\section{عرض ومناقشة النتايج الخاصة بالتشاؤل الريايع :}

ينص هذا التساؤل على ما التحديات المعاصرة التى تؤثز على السياحة الرياضية محلياً وعالمياً؟

ولإجابة على هذا التساؤل تم حساب الدرجة المقدرة والوزن النسبي لدرجة عينة البحث على عبارات استبيان السياحة الرياضية ورصدت نتائج ذلك فى الجدول التالي: 


\section{جدول (v)}

التكرارات والدرجة المقرة والوزن النسبي وكاب لاستجابات عينة البحث على المحو

الرابع (التحديات المعاصرة التى تؤثر على السياحة الرياضية محلياً وعالميا)

\begin{tabular}{|c|c|c|c|c|c|c|c|c|c|c|c|}
\hline \multirow[t]{2}{*}{ الدلالة } & \multirow[t]{2}{*}{ كاr } & \multirow{2}{*}{ 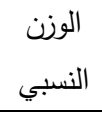 } & \multirow{2}{*}{ 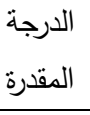 } & \multicolumn{2}{|c|}{ y } & \multicolumn{2}{|c|}{ الى حد ما } & \multicolumn{2}{|c|}{ ن ن مع } & \multirow[t]{2}{*}{ العبارة } & \multirow{2}{*}{5} \\
\hline & & & & $\%$ & s) & $\%$ & ك & $\%$ & كs & & \\
\hline$\cdots$ & Y17.V4 & $9 \leq . \wedge 9$ & $\varepsilon r V$ & $0 . r T$ & $\wedge$ & ร.TV & V & $9 \ldots$ & 1 o & 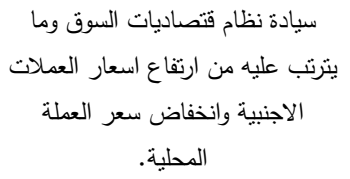 & 1 \\
\hline$\cdots$ & $r \cdot 1 . \wedge \Lambda$ & $9+.71$ & $\sum r \mid$ & V.rT & 11 & ร.TV & V & $\wedge \wedge . .$. & ITr & تعدد التكتلات لإقتصادية وتعظم & r \\
\hline$\cdots$ & INT.Or & $9 \uparrow . \vee \wedge$ & $\sum r r$ & $\varepsilon \ldots$ & 1 & $1 . .7 \mathrm{~V}$ & 17 & 10.r & 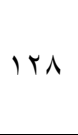 & 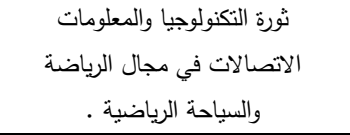 & r \\
\hline$\cdots$ & $r \cdot 1 .$. & $9 \leq . \leq \varepsilon$ & Ero & ะ.TV & v & V.ru & 11 & $\wedge \wedge . .$. & ITr & تدفق المعرفة بشكل متسارع ومتواصل & $\varepsilon$ \\
\hline$\cdots$ & $1 \leqslant 1 . Y \wedge$ & AV. 70 & rqs & $17 .$. & $T \varepsilon$ & $0 . \mu T$ & $\wedge$ & VA.TV & 111 & اقتصاد السوق المحلي وما يترتب عليه & 0 \\
\hline$\cdots$ & $101 . r \mathrm{r}$ & $9 \ldots$ & $\varepsilon .0$ & $1 . .7 \mathrm{~V}$ & 17 & 1. $7 \mathrm{~V}$ & $\pi$ & A.. .TV & $|r|$ & 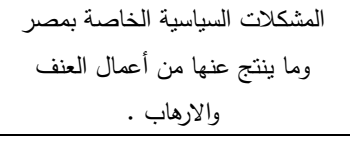 & 7 \\
\hline$\cdots$ & 10r.. E & & $\varepsilon \cdot r$ & IT.TV & 19 & $7.7 V$ & 1. & A..TV & $|r|$ & الأدنى لعجلات البطالة وانخفاض الحد & V \\
\hline$\cdots$ & 111.07 & qY. $\varepsilon \varepsilon$ & $\{17$ & ^... & ir & $7.7 V$ & 1. & ת & IrA & مكان لآخر & $\Lambda$ \\
\hline$\cdots$ & IVT.YA & qr... & $\leq 1 \leq$ & А... & ir & ^... & Ir & $\wedge \varepsilon \ldots$ & MY & ضعف النقة بين الثباب والقيادة . & 9 \\
\hline$\cdots$ & $r \leq \Lambda .0 r$ & $97.7 \mathrm{~V}$ & $\varepsilon r_{0}$ & $\varepsilon \ldots$ & 7 & r... & r & $9 \leq \ldots$ & $1 \leq 1$ & الزيادة السكانية . & 1 . \\
\hline$\cdots$ & TYT.YE & $9 \leq .7 V$ & 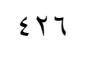 & $7.7 \mathrm{~V}$ & 1. & T.TV & $\varepsilon$ & $9 . .7 V$ & 4 1 1 & عدم المشاركة في اتخاذ القرار & 11 \\
\hline
\end{tabular}

يتضح من جدول (V) وجود فروق دالة احصائياً بين استجابات الأخصائيين الرياضيين عينة البحث على عبارات المحور الرابع (التحديات المعاصرة التى نؤثر على السياحة

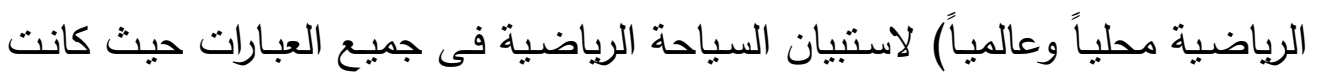

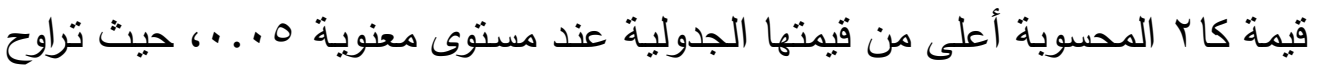

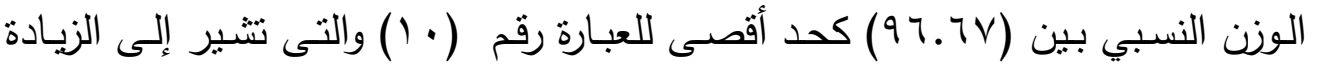


السكانية .، في حين بلغ الحد الأدنى للوزن النسبي (Av.07) للعبارة رقم (0) والتى تشير إلى اقتصاد السوق المحلي وما يترتب عليه من آثار اجتماعية وثقافية. ويرجع الباحثون هذه النتيجة إلى الظروف السياسية والاقتصادية التى تمر بها مصر أدي الى ارتفاع العملات الأجنبية وانخفاض العملة المحلية مما يؤثر على السياحة الرياضية بشكل واضح نتيجة عدم الاقبال على ممارسة مناشط السياحة الرياضية نتيجة الاضطرابات التى تمر بها مصر مما ينتج عنها من أعمال العنف والارهاب .

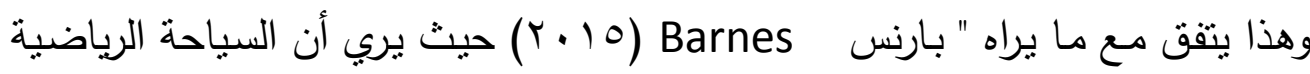

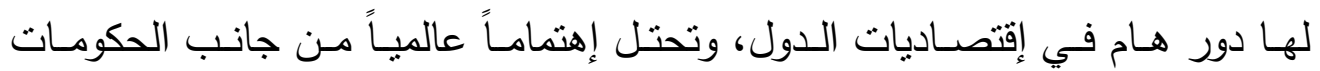
والخبراء، حيث الإصرار على أن الدولة التي أخذت في تطوير وتتمية القطاع السياحي فيها تأخذ طريقها نحو التتمية الإقتصادية وتحسين الهيكل الاقتصادي ويظهر ذلك في زيادة الإيرادات السياحية من النقد الأجنبي مما يعطي الافعـة اللازمـة للتنمية بتوفير أكبر قدر من العملات الأجنبية التي ينفقها السائحون خلال مدة إقامتهر.

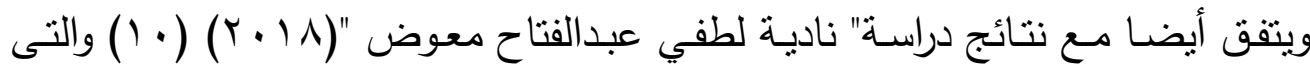

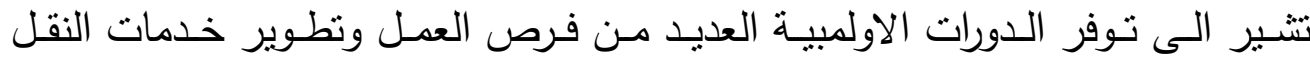
السياحي مما له تأثثير ايجابي على اقتصاد الدولة المستضيفة. وبهذا يتم الإجابة على التساؤل الرابع والذي ينص على ما التحديات المعاصرة التى تؤثر على السياحة الرياضية محلياً وعالمياً? الاستتتاجات:

أولاً : فيما يخص واقع السياحة الرياضية في جمهورية مصر العربية السياحة الرياضية تؤثر بشكل كبير على: - البيئة الإجتماعيـة والثقافيـة مـن خـله تبـادل العـادات والتقاليد والتقافات بين السائحين وسكان المدن. - - تسويق بعض السلع والمنتجات الصناعية الاخرى من خلال قلة تردد السائحين على هذه المنتجات. 
- توفير فرص عمل جيدة ضمن حدود القطاع السياحي.

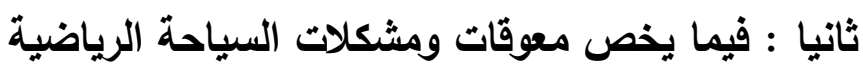

- - عدم وجود نتريع خاص بالسياحة الرياضية ضمن مجالات الاستثمار والتتمية

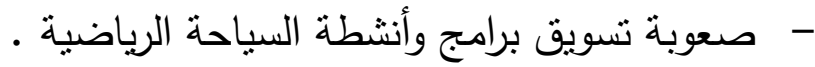

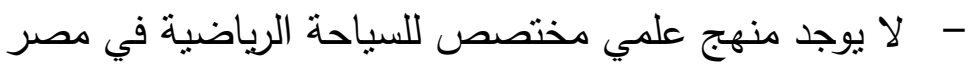

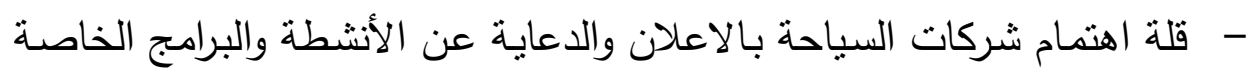
بالسياحة الرباضية المتوفرة داخل الدولة .

- عدم اقامة دورات للعاملين في مجال الاعلام الرياضي عن السياحة الرياضية

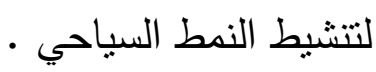

- الافتقار لوجود سياسـة تسويقية قادرة على توجيـه المنتج السياحى الرياضـى بشكل يتتاسب مع رغبات السوق المستهدف. - عدم توافر خدمات اعلامية كافية عن المسابقات الرياضية العالمية التى تقام في مصر لنتجيع وتحفيز السائحين من مختلف دول العالم لمشاهدتها. ثالثا : فيما يخص الامكانات المادية والبشرية في مجال السياحة الرياضية:

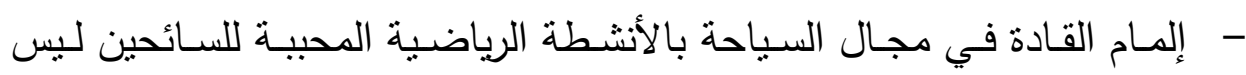

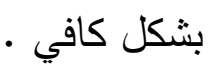

- - نقص البرامج التدريبية للعاملين بالقطاع السياحى وقلة العمالة المدربـة والمؤهلة فى بعض المنشآت التى تخدم النشاط الرياضى بمختلف الأماكن السياحية. - قلة توافر الكوادر المؤهلة لتتظيم المسابقات الرياضية للسائحين. - الأدوات والأجهزة الرياضية المتوفرة تحقق أهداف السياحة الرياضية. - المنشآت الرياضية الحالية صالحة لخدمة السياحة الرياضية المتميزة . رابعاً : فيما يخص التحديات المعاصرة التى تؤثر على السياحة الرياضية محلياً وعالمياً 


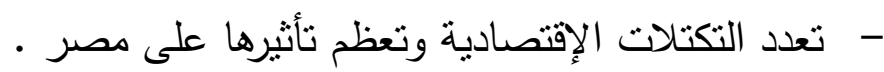

- - نظام اقتصاديات السوق وما يترتب عليه من ارتفاع اسعار العملات الاجنبية وانخفاض سعر العملة المحلية داخل مصر .

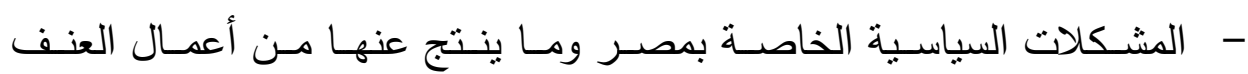
والارهاب.

- مشكلات البطالة وانخفاض الحد الأدنى للإجور • - مإن - الإزدحام وصعوبة الانتقال من مكان الى آخر - ل

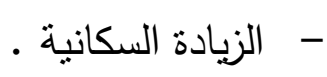
- - منعف البنية التحتية اللازمة لخدمة السياحة الرياضية. التوصيات - - توفير أمـاكن خاصـة بـالإعلاميين في أمساكن الممارسـات الرياضية وتزويدها بكافة الإمكانات.

- - - ضرورة الإستعانة والإستفادة بالخبراء العالميين في مجال السياحة الرياضية .

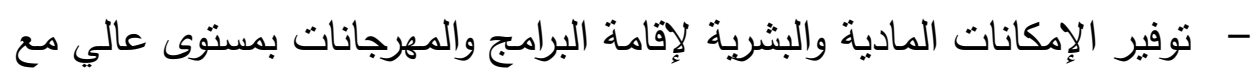
ضرورة التسويق والترويج لتلك البرامج. - - ضرورة تتوع البرامج الرياضية المقدمة للسائحين وعدم الإقتصار على رياضـة لئس بعينها

- توفير الإمكانات المادية التي تساعد على إستغلال الموارد الطبيعية .

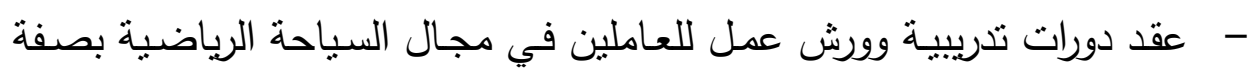
مستمرة. - - إقامـة المـؤتمرات والنـدوات الخاصـة بالسـياحة الرياضـية لتوضـيح الأهـداف وعرض الفرص والتهديدات. 
- - توفير الكوادر المؤهلة في مجال السياحة الرياضية من خلال توفير تخصص سياحة رياضية في كليات التربية الرياضية للقدرة على وضـع برامج السياحة

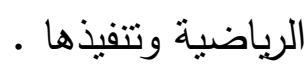

- الاهتمام بالدعاية والاعلان عن مناشط وبرامج السياحة الرياضية لزيادة الاقبال عليها من جميع انحاء العالم مما يؤثز ايجابياً على الاقتصاد القومي . - - توفير كافة الأدوات والأجهزة التى تتتاسب مع جميع مناشط السياحة الرياضية 


\section{قائمة المراجع \\ أولا: المراجع باللغة العربية}

1. أبوبكر عوني عطبة : التتظيم الدولي للسباحة الرياضية(نحو إنشـاء منظمـة

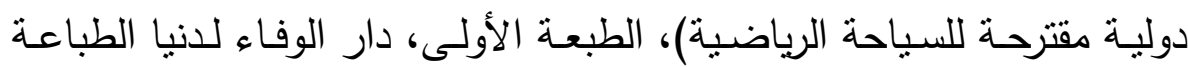

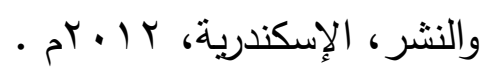

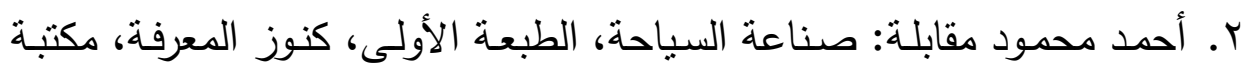

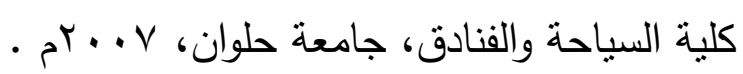

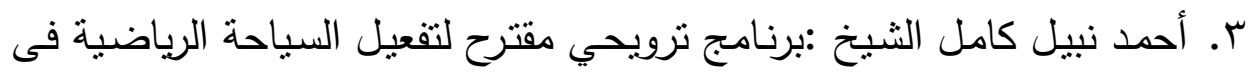
ج•م•ع ، رسـالة دكتوراه غير منشورة، كلية التربية الرياضية، جامعة الزقازيق

$$
\cdot 5114
$$

ع. أحمد نبيل كامل الثيخ: دور السياحة ال رياضية فى تتمية الموارد بالإتحادات الرياضية بجمهورية مصر العربية، رسالة ماجستير غير منشورة، كلية التربية

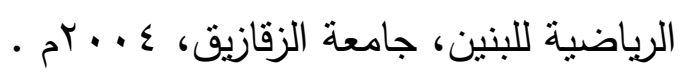

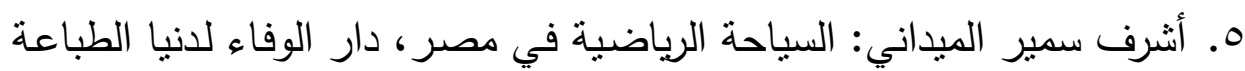

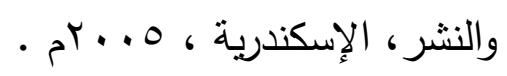

T. أنيس فتحى، الإمـارات إلى أين ..ستشـراف التحديات والمخاطرعلى مدىه

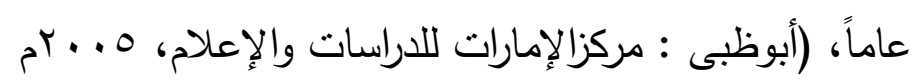

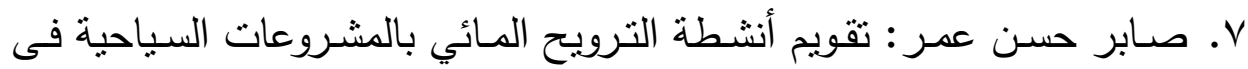
جمهورية مصر العربية، رسالة ماجستير، كلية التربية الرياضية للبنين بالهرم،

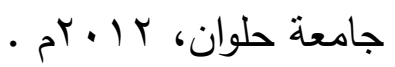

^. مــدت قاسـم، أحمـد عبـد الفتـاح :السـياحة الرياضـية والمنتجعـات الصـحية

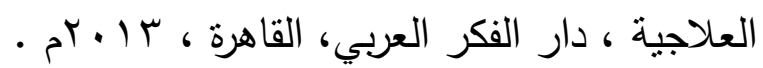

9. منال شوقي عبد المعطي: دراسة في مدخل علم السياحة، الطبعة الأولى، دار

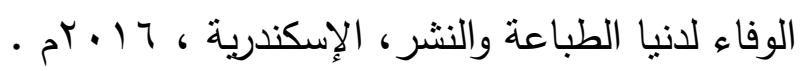


• ا. نادية لطفي عبدالقتاح معوض :تتظيم الدورات الأولمبية وانعكاساتها إقتصادياً

على الدولة المضيفة، رسـالة ماجستير غير منشورة ، كليـة التربية الرياضية

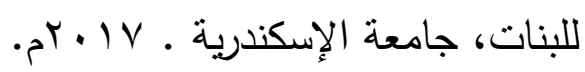

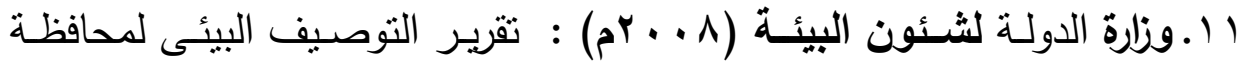

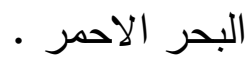

r ا. باسبين الكحلي: دور السياحة في التتميـة الاقتصـادية والإجتماعيـة والتقافيـة،

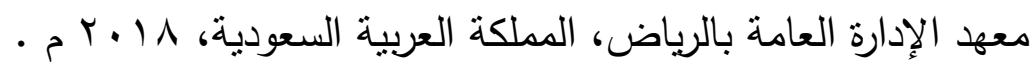

$$
\text { ثانيا: المراجع باللغة الاجنبية }
$$

13. Heather J. Gibson: Sport Tourism, Published by: Rout ledge, $24^{\text {th }}$ December 2017

14.Freyer,W: Sport und Tourismus, Megamarkte In Der Wissen Schaftlchen Disk ussion In Troslen, G, 2010

15.Dawid .J. delivers: Sport and Tourism to Stimulate Development world conference on sports and tourism, Barcelona, SPAIN feb, 2012.

16.Barnes: Sports, Tourism, and Economic Development, Cleveland State University, July, 12-14, 2005. 